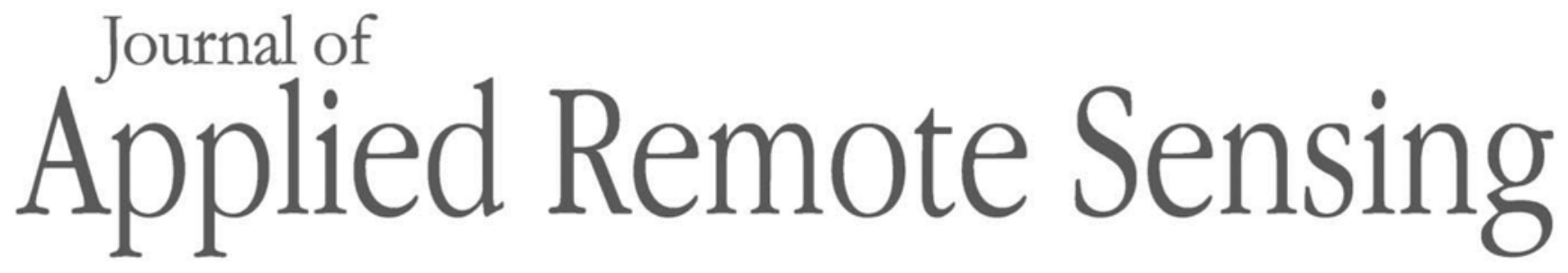

RemoteSensing.SPIEDigitalLibrary.org

\title{
Vegetation classification of Coffea on Hawaii Island using WorldView-2 satellite imagery
}

Julie Gaertner

Vanessa Brooks Genovese

Christopher Potter

Kelvin Sewake

Nicholas C. Manoukis 


\title{
Vegetation classification of Coffea on Hawaii Island using WorldView-2 satellite imagery
}

\author{
Julie Gaertner, ${ }^{\text {a,b }}$ Vanessa Brooks Genovese, ${ }^{\text {c }}$ Christopher Potter, ${ }^{\text {d }}$ \\ Kelvin Sewake, ${ }^{\mathrm{e}}$ and Nicholas C. Manoukis ${ }^{\mathrm{a}}$ 网 \\ ${ }^{a}$ Daniel K. Inouye United States Pacific Basin Agricultural Research Center, United States \\ Department of Agriculture-Agricultural Research Service, Hilo, Hawaii, United States \\ ${ }^{b}$ University of Hawaii at Manoa, College of Tropical Agriculture and Human Resources, \\ Hilo, Hawaii, United States \\ ${ }^{\mathrm{c} C a l i f o r n i a}$ State University at Monterey Bay, Division of Science and Environmental Policy, \\ Seaside, California, United States \\ ${ }^{\mathrm{d} N A S A}$ Ames Research Center, Earth System Science, Moffett Field, California, United States \\ ${ }^{\mathrm{e}}$ University of Hawaii at Manoa, College of Tropical Agriculture and Human Resources, \\ Honolulu, Hawaii, United States
}

\begin{abstract}
Coffee is an important crop in tropical regions of the world; about 125 million people depend on coffee agriculture for their livelihoods. Understanding the spatial extent of coffee fields is useful for management and control of coffee pests such as Hypothenemus hampei and other pests that use coffee fruit as a host for immature stages such as the Mediterranean fruit fly, for economic planning, and for following changes in coffee agroecosystems over time. We present two methods for detecting Coffea arabica fields using remote sensing and geospatial technologies on WorldView-2 high-resolution spectral data of the Kona region of Hawaii Island. The first method, a pixel-based method using a maximum likelihood algorithm, attained $72 \%$ producer accuracy and $69 \%$ user accuracy (68\% overall accuracy) based on analysis of 104 ground truth testing polygons. The second method, an object-based image analysis (OBIA) method, considered both spectral and textural information and improved accuracy, resulting in $76 \%$ producer accuracy and $94 \%$ user accuracy (81\% overall accuracy) for the same testing areas. We conclude that the OBIA method is useful for detecting coffee fields grown in the open and use it to estimate the distribution of about 1050 hectares under coffee agriculture in the Kona region in 2012. (c) The Authors. Published by SPIE under a Creative Commons Attribution 3.0 Unported License. Distribution or reproduction of this work in whole or in part requires full attribution of the original publication, including its DOI. [DOI: 10.1117/1.JRS.111.046005]
\end{abstract}

Keywords: coffee berry borer; remote sensing; object-based image analysis.

Paper 170347 received Apr. 24, 2017; accepted for publication Sep. 26, 2017; published online Oct. 13, 2017.

\section{Introduction}

Coffee is a commodity of major importance for tropical agriculture, with about 8.8 million tonnes of green beans produced annually from over 10 million hectares under cultivation worldwide in 2013. It is estimated that 125 million people depend on coffee for their livelihoods, ${ }_{\text {and }}$ its importance has only grown with increasing popularity of coffee and its role as the leading commodity of the "fair trade" sociopolitical movement of the last 30 years. ${ }^{\text {I }}$ Despite its centrality, coffee production is under threat from a variety of sources, including market price collapses, pollinator declines, and pests and pathogens.

A remote mapping method would be of value to those studying coffee production and pest control for Coffea arabica, one of the two major coffee species grown worldwide. Field data collection and surveying for coffee plantations, while potentially more accurate, is costly and time consuming. A remote sensing method would allow higher frequency and lower cost

*Address all correspondence to: Nicholas C. Manoukis, E-mail: nicholađmanoukis@ardusdagov 
estimates of areas under coffee cultivation and changes in these areas over time. Spatial analysis can be useful for management and control of pests as it would allow detection of unmanaged feral coffee plants, which if ignored could harbor populations and therefore counteract efforts to control the spread of pests. It would also be of interest to national and international agricultural planning agencies. Finally, accurate detection and characterization of coffee patches could be an important component of models of coffee agroecosystems that model the growth and development as well as the dynamics of coffee crops. ${ }^{0}$ These models are important because they are used to develop management options for coffee production.

There have been several studies over the years in tropical regions aimed at classifying coffee plants using remotely sensed data, with varied classification accuracy results. 매 $\mathrm{High}$ variation results from cloud cover in tropical regions and from the need for high spatial resolution imagery to identify individual plants, as well as to distinguish coffee from other vegetation. For example, Landsat data have been used to classify coffee plants in Costa Rica with a 65\% accuracy overall [I] and in El Salvador with a 76.7\% accuracy overall, although the authors recognized that they had only a small sample dataset for the accuracy assessment. ${ }^{17}$ More recently, in Brazil, SPOT (Satellite for observation of Earth) data analyzed via convolutional neural networks were

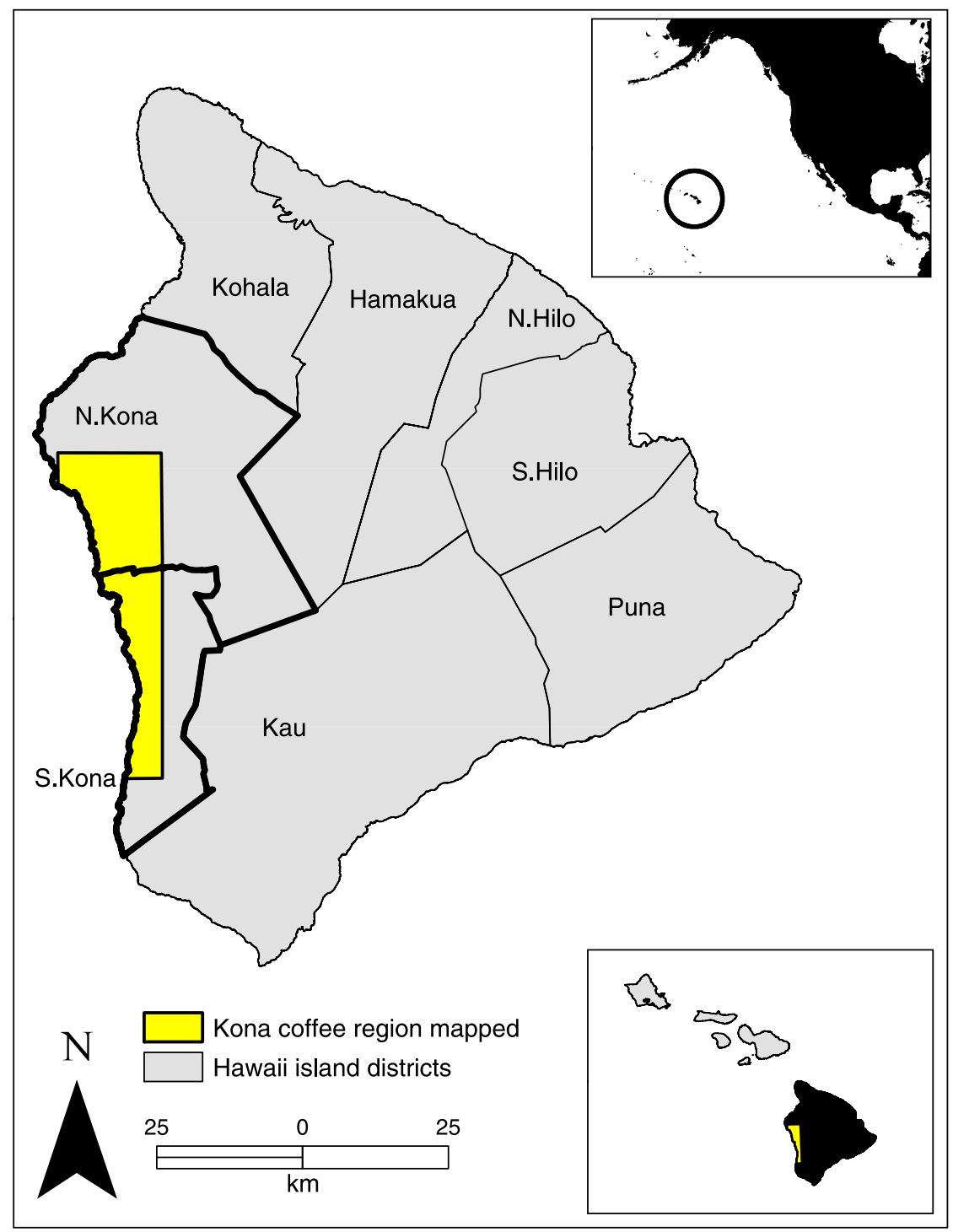

Fig. 1 Hawaii Island district map with North and South Kona districts highlighted in thick black line and coffee region mapped in yellow. Lower right subpanel: Hawaii Island relative to the Hawaiian archipelago. Upper right subpanel: Hawaiian archipelago relative to the continental United States. 
Table 1 DigitalGlobe WorldView-2 satellite spectral resolution specifications. The panchromatic spectral band has $46 \mathrm{~cm}$ spatial resolution, while the multispectral bands have $1.85-\mathrm{m}$ spatial resolution.

\begin{tabular}{ccccc}
\hline \hline Description & Band ID & Spectral resolution $(\mathrm{nm})$ & Spatial resolution \\
\hline Coastal blue & 1 & 400 to 450 & $1.85 \mathrm{~m}$ \\
Blue & 2 & 450 to 510 & $1.85 \mathrm{~m}$ \\
Green & 3 & 510 to 580 & $1.85 \mathrm{~m}$ \\
Yellow & 4 & 585 to 625 & $1.85 \mathrm{~m}$ \\
Red & 5 & 630 to 690 & $1.85 \mathrm{~m}$ \\
Red-edge & 6 & 705 to 745 & $1.85 \mathrm{~m}$ \\
NIR1 & 7 & 770 to 895 & $1.85 \mathrm{~m}$ \\
Panchromatic band & 8 & 860 to 1040 & $1.85 \mathrm{~m}$ \\
\hline \hline
\end{tabular}

used to get very good classification accuracy results of $91.8 \%$ [3 However, this method may be difficult to apply to other regions as it requires "careful fine-tuning" of the algorithms and knowledge of neural networks. 10

The objective of this study was to identify an efficient methodology using remote sensing and geospatial technologies for detecting coffee plants (Coffea spp.) and mapping the distribution on Hawaii Island. The pilot study area is located in the Kona coffee belt in the North and South Kona Districts of Hawaii Island (Fig. (1). 8-band multispectral visible to near-infrared high spatial resolution ( $2 \mathrm{~m}$ ) WorldView-2 satellite imagery (WV2) was used for this analysis. A maximum likelihood pixel-based classification algorithm and an algorithm based on object-based image analysis (OBIA) were tested for this study.

\section{Study Area}

The Hawaii coffee industry is relatively small but enjoys an excellent reputation. There is coffee production on Kauai, Oahu, Molokai, Maui, and Hawaii Islands. On Hawaii Island, coffee is primarily grown in the Kona and Kau districts. ${ }^{-4}$ Kona coffee commands a premium price on the world specialty market based on its geographic origin and quality. ${ }^{\text {[5 }}$ The introduction in 2010 of the coffee berry borer [Hypothenemus hampei (Ferrari)], a major pest of coffee worldwide, has shaken the industry in Kona, and Hawaii generally, and spurred interest in precision agriculture to combat the threat.

Kona's "coffee belt" is a suitable location to test methods of remote-detection of coffee plants because it is environmentally heterogeneous. A two mile-wide strip of agricultural zone exists at elevations between 215 and $610 \mathrm{~m}$. The coffee belt area mapped includes $514 \mathrm{~km}^{2}$ or $\sim 51,400$ hectares of the North and South Kona Districts with the elevation ranging from sea level to $2438 \mathrm{~m}$ (Fig. 1).

\section{Materials and Methods}

\subsection{Overview}

Image classification was conducted using a maximum likelihood (pixel-based) and an objectbased algorithm in ENVI 5.2 and 5.3. The goal was to test both classification methods for mapping coffee trees growing in this Kona coffee belt region of Hawaii Island from high-resolution remotely sensed data. 


\subsection{Satellite Imagery}

WV2 was launched in 2009 by DigitalGlobe Inc. and provides image data with a multispectral spatial resolution of $1.85 \mathrm{~m} \mathrm{GSD}$ at nadir and 2.07 GSD at $20 \mathrm{deg}$ off-nadir and panchromatic spatial resolution of $46 \mathrm{~cm}$ GSD at nadir and $0.52 \mathrm{~cm}$ GSD at $20 \mathrm{deg}$ off-nadir. This highresolution satellite imagery provides eight spectral bands including coastal blue, blue, green, yellow, red, red edge, NIR 1 (near-infrared), and NIR 2 (Table 1). The satellite operates at an altitude of $770 \mathrm{~km}$, collecting almost 1 million $\mathrm{km}^{2}$ of imagery per day, and circles the globe in 1.1 days.

The multispectral satellite imagery used in this study was recorded with 8-bit quantization, with acquisition dates for the study area including December 16 and 22, 2012, for the North and South Kona Districts of Hawaii Island (Fig. 11). Orthoimagery 2012 WorldView-2 Hawaii Island Mosaic, Release 2, used in this analysis was provided by USDA-NRCS National Geospatial Center of Excellence and delivered to the Spatial Data Analysis and Visualization Lab (SDAV) at the University of Hawaii at Hilo in July 2013. The Pan Sharpen mosaic is a combination of panchromatic and multispectral bands (bands 2-3-4) that was color balanced by USDANRCS National Geospatial Center of Excellence.

Individual coffee trees span $\sim 4 \mathrm{ft}(\sim 1.5 \mathrm{~m})$, while coffee fields span several hundred meters. As a general rule, spatial resolution for digital imagery should be one-half the width of the smallest tree of interest for analysis. ${ }^{1}$ Based on this, WV2 satellite imagery (1.85 m resolution/multispectral) may not be optimal for detecting individual coffee plants in an open field of mixed vegetation, but it is adequate for detecting coffee plantation fields. The panchromatic color balanced imagery provided a higher spatial resolution $(46 \mathrm{~cm})$ as an aid in visually cross-checking the accuracy of multispectral eight-band pixel-based classification for commission and omission errors.

\subsection{Ground Truth and Accuracy Assessment}

To calibrate the classification training pixels, evaluate classification results, and confirm accuracy and independence of the testing pixels, we collected ground-truth reference data using a handheld GPS unit (Rino 655, Garmin International, Olathe, Kansas) by physically visiting a subset of sites. Photographs were collected with GPS data to confirm land use classes and plant species identification for building robust pixel training classes (Table E) and independent

Table 2 Supervised vegetation classification training pixels and points used in ENVI representing land cover classes identified within the North and South Kona Districts of Hawaii island study area. The majority of OBIA points are one pixel in size (see text for more details).

\begin{tabular}{lcc}
\hline \hline Land cover class & Training pixels (ML) & Training points (OBIA) \\
\hline Coffee & 590 & 64 \\
Macadamia & 395 & 2254 \\
Mixed forest & 475 & 3677 \\
Grass & 198 & 35 \\
Monkeypod & 196 & 75 \\
No vegetation & 165 & 56 \\
Urban & 174 & 225 \\
Roads & 173 & 46 \\
Water & - & 10 \\
Bare ground & - & 4 \\
Total & 2366 & 6446 \\
\hline \hline
\end{tabular}


accuracy assessment polygons/pixels (Table 3). In addition to 2012 WV2 satellite imagery and GPS ground reference data, we also used high-resolution $(15 \mathrm{~cm}) 2012$ Pictometry Online (POL) aerial imagery to confirm the presence or absence of coffee and to delineate training and testing pixels and classes. We analyzed GPS and Pictometry data in ArcGIS 10.2 (Esri Corp., Redlands, California) and ENVI 5.2 (Harris Geospatial Corp., Melbourne, Florida) to assist in developing training pixels and accuracy testing pixels and to cross-check the coffee classification map results.

We selected a total of 2366 training pixels covering the geographic extent of the area mapped (Fig. (1) to train the ENVI software to detect coffee plants using the maximum likelihood vegetation classification algorithm. Pixels were selected haphazardly from areas that were visually uniform in the ground truth data. These same training areas were referenced for the OBIA classification as well as additional training areas chosen visually to improve the classification. The training pixels used were derived from 8 land cover classes identified using 2012 WV2 satellite imagery (1.85-m multispectral/46-cm panchromatic resolution), 2012 POL aerial imagery (15 $\mathrm{cm}$ resolution), and GPS field verification within the study area and included (1) coffee, (2) macadamia nut, (3) mixed forest, (4) grass, (5) monkeypod, (6) no vegetation, (7) urban, and (8) roads. For the OBIA analysis, two additional classes were included: (9) water and (10) bare ground (naked soil, not including lava fields, which were included in "no vegetation") (Table 2).

We conducted accuracy assessments of both coffee detection methods using the same set of pixel/polygon data (a testing set) to quantify the reliability of the classified map results [2] (Table B). This testing set was separate from the training set (Table 21) to avoid overestimating or misrepresenting classification accuracy ${ }^{27}$ For accuracy assessments, we delineated in ENVI 104 independent polygons or 18,360 testing pixels (Table 3) representing the same 8 land use classes used for the maximum likelihood training method. We cross-checked each testing polygon for species/class homogeneity and spatial autocorrelation with maximum likelihood training pixels to confirm that testing pixels/polygons were independent from training pixels. This independent validation was done using high-resolution $(15 \mathrm{~cm})$ POL aerial imagery with acquisition dates spanning from January 11 through December 29, 2012, with an ArcGIS user interface developed by Pictometry International Corp. The WV2 imagery acquisition dates for the classification analysis were December 16 and 22, 2012, for the North and South Kona Districts of Hawaii Island. We calculated final confusion matrices in ENVI by comparing the independently verified testing pixels with the final classification results displayed in the results section of this report (Tables 5, 6).

Table 3 Accuracy assessment testing pixels/polygons used in the confusion matrix analysis in ENVI. The same polygons/pixels were used for testing both the maximum likelihood and OBIA classifiers.

\begin{tabular}{lcr}
\hline \hline Class & Polygons & Pixels \\
\hline Coffee & 22 & 4085 \\
Macadamia & 21 & 4578 \\
Mixed forest & 15 & 5066 \\
Grass & 15 & 1881 \\
Monkeypod & 16 & 655 \\
No vegetation & 5 & 1349 \\
Urban & 5 & 372 \\
Roads & 5 & 374 \\
Total & 104 & 18,360 \\
\hline \hline
\end{tabular}


Table 4 Confusion matrix results for the pixel-based and OBIA coffee classification with producer and user accuracy (pixel overall accuracy $=68.15 \%$, pixel kappa coefficient $=0.6081$, OBIA overall accuracy $=80.62$, and OBIA kappa coefficient $=0.7563$ ). Producer and user accuracy estimates for each method are given in percentages, values in bold are for coffee.

\begin{tabular}{lcccc}
\hline \hline Map class & $\begin{array}{c}\text { Pixel producer } \\
\text { accuracy }\end{array}$ & $\begin{array}{c}\text { Pixel user } \\
\text { accuracy }\end{array}$ & $\begin{array}{c}\text { OBIA producer } \\
\text { accuracy }\end{array}$ & $\begin{array}{c}\text { OBIA user } \\
\text { accuracy }\end{array}$ \\
\hline Coffee & $\mathbf{7 1 . 8 2}$ & 69.39 & $\mathbf{7 5 . 8 9}$ & 94.40 \\
Macadamia & 36.39 & 66.14 & 92.62 & 81.84 \\
Mixed forest & 75.82 & 71.78 & 86.79 & 88.67 \\
Grass & 80.60 & 76.22 & 71.03 & 50.72 \\
Monkeypod & 79.24 & 26.17 & 72.37 & 93.86 \\
No veg & 98.67 & 91.48 & 49.15 & 74.58 \\
Urban & 93.55 & 77.51 & 98.39 & 61.31 \\
Roads & 95.99 & 93.01 & 60.43 & 72.67 \\
\hline \hline
\end{tabular}

Table 5 ENVI confusion matrix results for the pixel-based classified image using 104 independent testing polygons across the Kona coffee belt study area. The labels in rows represent the training map classes, and the labels in columns represent the ground truth testing classes. The cells in between give the producer accuracy in percent assigned to each class, and the numbers in brackets are the number of pixels assigned to each class. Parentheses highlight testing set pixels that are correctly classified in the map. The overall accuracy is the diagonal sum of correctly classified pixels divided by total number of all pixels. User accuracy is in rows, and producer accuracy data is in columns.

\begin{tabular}{|c|c|c|c|c|c|c|c|c|c|}
\hline \multirow[b]{2}{*}{$\begin{array}{l}\text { Map } \\
\text { class }\end{array}$} & \multicolumn{9}{|c|}{ Ground truth pixels } \\
\hline & Coffee & Macnut & Forest & Grass & Mpod & No veg & Urban & Roads & $\begin{array}{l}\text { Total } \\
\text { pixels }\end{array}$ \\
\hline Coffee & $\begin{array}{c}71.8 \\
(2934)\end{array}$ & $18.5(845)$ & $7.7(390)$ & $1.1(20)$ & $5.8(38)$ & $0(0)$ & $0(0)$ & $0.3(1)$ & 4228 \\
\hline Macnut & $10.1(413)$ & $\begin{array}{c}36.4 \\
(1666)\end{array}$ & $5.9(298)$ & $4.4(83)$ & $9.0(59)$ & $0(0)$ & $0(0)$ & $0(0)$ & 2519 \\
\hline Forest & $3.4(138)$ & $24.0(1099)$ & $\begin{array}{c}75.8 \\
(3841)\end{array}$ & $12.4(233)$ & $5.8(38)$ & $0(0)$ & $0.3(1)$ & $0.3(1)$ & 5351 \\
\hline Grass & $7.3(298)$ & $1.4(62)$ & $2.0(103)$ & $\begin{array}{c}80.6 \\
(1516)\end{array}$ & $0.3(1)$ & $0.7(9)$ & $0(0)$ & $0(0)$ & 1989 \\
\hline Mpod & $5.3(216)$ & $19.0(870)$ & $7.0(352)$ & $1.4(26)$ & $\begin{array}{l}79.2 \\
(519)\end{array}$ & $0(0)$ & $0(0)$ & $0(0)$ & 1983 \\
\hline No veg & $0.3(13)$ & $0.5(22)$ & $1.3(67)$ & $0.2(3)$ & $0(0)$ & $\begin{array}{c}98.7 \\
(1331)\end{array}$ & $2.7(10)$ & $2.4(9)$ & 1455 \\
\hline Urban & $1.8(73)$ & $0.3(14)$ & $0.2(9)$ & $0(0)$ & $0(0)$ & $0.3(1)$ & $\begin{array}{l}93.6 \\
(348)\end{array}$ & $1.1(4)$ & 449 \\
\hline Roads & $0(0)$ & $0(0)$ & $0.1(6)$ & $0(0)$ & $0(0)$ & $0.6(8)$ & $3.5(13)$ & $\begin{array}{c}96.0 \\
(359)\end{array}$ & 386 \\
\hline $\begin{array}{l}\text { Total } \\
\text { pixels }\end{array}$ & 4085 & 4578 & 5066 & 1881 & 655 & 1349 & 372 & 374 & 18,360 \\
\hline
\end{tabular}


Table 6 ENVI confusion matrix results for the OBIA classified image using 104 independent testing polygons across the Kona coffee belt study area. The labels in rows represent the training map classes, and the labels in columns represent the ground truth testing classes. The cells in between give the producer accuracy in percent assigned to each class, and the numbers in brackets are the number of pixels assigned to each class. Parentheses highlight testing set pixels that are correctly classified in the map. The overall accuracy is the diagonal sum of correctly classified pixels divided by total number of all pixels. User accuracy is in rows, and producer accuracy data is in columns.

\begin{tabular}{|c|c|c|c|c|c|c|c|c|c|}
\hline \multirow{2}{*}{$\begin{array}{l}\text { Map } \\
\text { class }\end{array}$} & \multicolumn{9}{|c|}{ Ground truth pixels } \\
\hline & Coffee & Macnut & Forest & Grass & Mpod & No veg & Urban & Roads & Total pixels \\
\hline Coffee & $\begin{array}{c}75.89 \\
(3100)\end{array}$ & $0(0)$ & $0(0)$ & $\begin{array}{c}6.96 \\
(131)\end{array}$ & $\begin{array}{l}8.09 \\
(53)\end{array}$ & $0(0)$ & $0(0)$ & $0(0)$ & 3284 \\
\hline Macnut & $\begin{array}{l}3.97 \\
(162)\end{array}$ & $\begin{array}{c}92.62 \\
(4240)\end{array}$ & $\begin{array}{l}13.21 \\
(669)\end{array}$ & $\begin{array}{l}2.13 \\
(40)\end{array}$ & $\begin{array}{l}9.92 \\
(65)\end{array}$ & $0(0)$ & $1.34(5)$ & $0(0)$ & 5181 \\
\hline Forest & $0.76(31)$ & $\begin{array}{l}5.29 \\
(242)\end{array}$ & $\begin{array}{c}86.79 \\
(4397)\end{array}$ & $\begin{array}{l}12.01 \\
(226)\end{array}$ & $\begin{array}{l}9.62 \\
(63)\end{array}$ & $0(0)$ & $0(0)$ & $0(0)$ & 4959 \\
\hline Grass & $\begin{array}{l}19.07 \\
(779)\end{array}$ & $0(0)$ & $0(0)$ & $\begin{array}{c}71.03 \\
(1336)\end{array}$ & $0(0)$ & $\begin{array}{l}38.47 \\
(519)\end{array}$ & $0(0)$ & $0(0)$ & 2634 \\
\hline Mpod & $0.32(13)$ & $0(0)$ & $0(0)$ & $\begin{array}{l}0.96 \\
(18)\end{array}$ & $\begin{array}{l}72.37 \\
(474)\end{array}$ & $0(0)$ & $0(0)$ & $0(0)$ & 505 \\
\hline No veg & $0(0)$ & $2.10(96)$ & $0(0)$ & $\begin{array}{c}6.91 \\
(130)\end{array}$ & $0(0)$ & $\begin{array}{l}49.15 \\
(663)\end{array}$ & $0(0)$ & $0(0)$ & 889 \\
\hline Urban & $0(0)$ & $0(0)$ & $0(0)$ & $0(0)$ & $0(0)$ & $6.15(83)$ & $\begin{array}{l}98.39 \\
(366)\end{array}$ & $\begin{array}{l}39.57 \\
(148)\end{array}$ & 597 \\
\hline Roads & $0(0)$ & $0(0)$ & $0(0)$ & $0(0)$ & $0(0)$ & $\begin{array}{l}6.23 \\
(84)\end{array}$ & $0.27(1)$ & $\begin{array}{l}60.43 \\
(226)\end{array}$ & 311 \\
\hline Total pixels & 4085 & 4578 & 5066 & 1881 & 655 & 1349 & 372 & 374 & 18,360 \\
\hline
\end{tabular}

\subsection{Details on Classification Methods}

We used a maximum likelihood estimation algorithm including all eight spectral bands to classify coffee by assigning each image pixel to a landcover class. 3 Maximum likelihood assigns pixels to classes following parametrization assuming that the values in each band are normally distributed, which we verified visually for our training areas using the histogram facility in ENVI 5.2. The maximum likelihood classifier operates on each pixel independently.

By contrast, the OBIA analysis we employed uses a set of pixels to classify imagery based on both the average spectral information from the set pixels and on geometric features (such as size, shape, and texture) of objects imaged by the set of pixels. The example based feature extraction tool in ENVI 5.3, considered a supervised OBIA classification technique in that the user selects the training objects that are used to classify the image, was used for this study.

Discrete steps in the OBIA process included image segmentation, selecting training data, selecting attributes for classification, and selecting a classification algorithm. Segmentation is the process of partitioning an image into objects by grouping neighboring pixels with common values. For this analysis, the edge detection segmentation algorithm with a scale level of 35.0 and the full lambda schedule merge algorithm with a level of 95.0 was used based on the red-edge band and a texture kernel size of 5 to best detect and delineate different vegetation types as recommended in the ENVI documentation. ${ }^{32}$ The next step was to select training data, or examples, for the supervised classification. The software could not load a previously built training dataset into the FX classification tool; therefore, the same training dataset that was used for the pixel-based classification could not be used. Instead, new training areas were manually selected based on the imagery by referencing the previous training dataset. The FX classification tool 
allows for manual selection of training areas based on a preanalysis segmentation, which creates a set of polygons created for the entire image. When the user selects training points, the polygon around each point is selected by the tool and added to the training set. For this reason, there were a larger number of pixels used in training the OBIA method compared with the ML method (Table 2). The OBIA training dataset we used comprised 164 polygons and 6446 points (6468 pixels; 22 points fell between pixels and were averaged to make points) with an overall average of 39 points per polygon.

We used the selected areas to train a support vector machine (SVM) model within the OBIA pipeline. SVM is a supervised classification method derived from statistical learning theory that often yields good classification results from complex and noisy data. It separates the classes with a decision surface that maximizes the margin among the classes.2724 The SVM model used in ENVI uses the pairwise classification strategy for multiclass classification. The kernel-type setting used for this analysis was a third-order polynomial, as described by

$$
K\left(x_{i} x_{j}\right)=\left(g x_{i}^{T} x_{j}+r\right)^{d}, \quad g>0,
$$

where $g$ is the gamma term in the kernel function, $d$ is the polynomial degree term in the kernel function, and $r$ is the bias term in the kernel function. The gamma, bias, and penalty parameters were hand tuned and set to $0.03,1$, and 100 , respectively. The penalty parameter controls the degree of misclassification in the model.

\section{Results and Discussion}

Direct comparison of results from the pixel-based and OBIA methods is complicated by the fact that each could potentially be further tuned, that additional training areas might improve one or the other, and that applying these in a different parts of the world might lead to different results. Despite this complexity, the analyses conducted are typical for the tools selected, and the results for each method are useful for guiding others attempting to classify coffee plantations from satellite imagery. The accuracy results for coffee were better using the OBIA technique in ENVI's feature extraction tool (76\% producer accuracy and $94 \%$ user accuracy) compared with the pixel-based maximum likelihood approach (72\% producer accuracy and $69 \%$ user accuracy), as shown in Table 4 . Although the pixel-based maximum likelihood supervised classification algorithm produced reasonable results in terms of coffee classification with overall accuracy $(68 \%)$ and kappa coefficient $(0.6081)$ (Tables $\square$ and 5, respectively), it did not pick out contiguous areas of coffee very well, as seen in the classification map of the coffee in the Kona coffee region. The map is difficult to interpret as pixels identified as coffee appear over the entire landscape (Fig. [2). In contrast, the object-based feature extraction tool in ENVI provided better results, both in terms of overall accuracy (81\%) and kappa coefficient (0.7563) (Tables $\$$ and 6 , respectively) and because it delivered a map with clear coffee fields. We also note that the OBIA classifier should be more resistant to shifts in the spectral signature of coffee plants over space or between years, which has been hypothesized to occur based on environmental conditions.

Further examination of Table $⿴$ indicates that the OBIA classifier outperformed the pixelbased classifier in some of the most abundant cover classes in the study area besides coffee, including macadamia and mixed forest. However, in some of the less-represented classes such as roads, the pixel-based classifier was more accurate. This is possibly because the spectral signature of this class is distinct, favoring spectral-only pixel classifiers compared with the OBIA method, which also considered less-distinct shape information. This suggests that, while the OBIA method is superior for detecting coffee, it might be worth eliminating some spectrally separable classes before application, especially in areas with many roadways, bare ground, and urban areas.

Some of the inaccuracies found in both classification maps contributing to commission and omission errors may be due to the lack of a unique spectral signature detected in the target species coffee from all other species found in this landscape using the 8-band WV2 imagery. There was an overlap of spectral signatures, or weak spectral separability, found between macadamia nut trees and coffee trees $(-0.732)$, which are also commonly found on the same fields. 

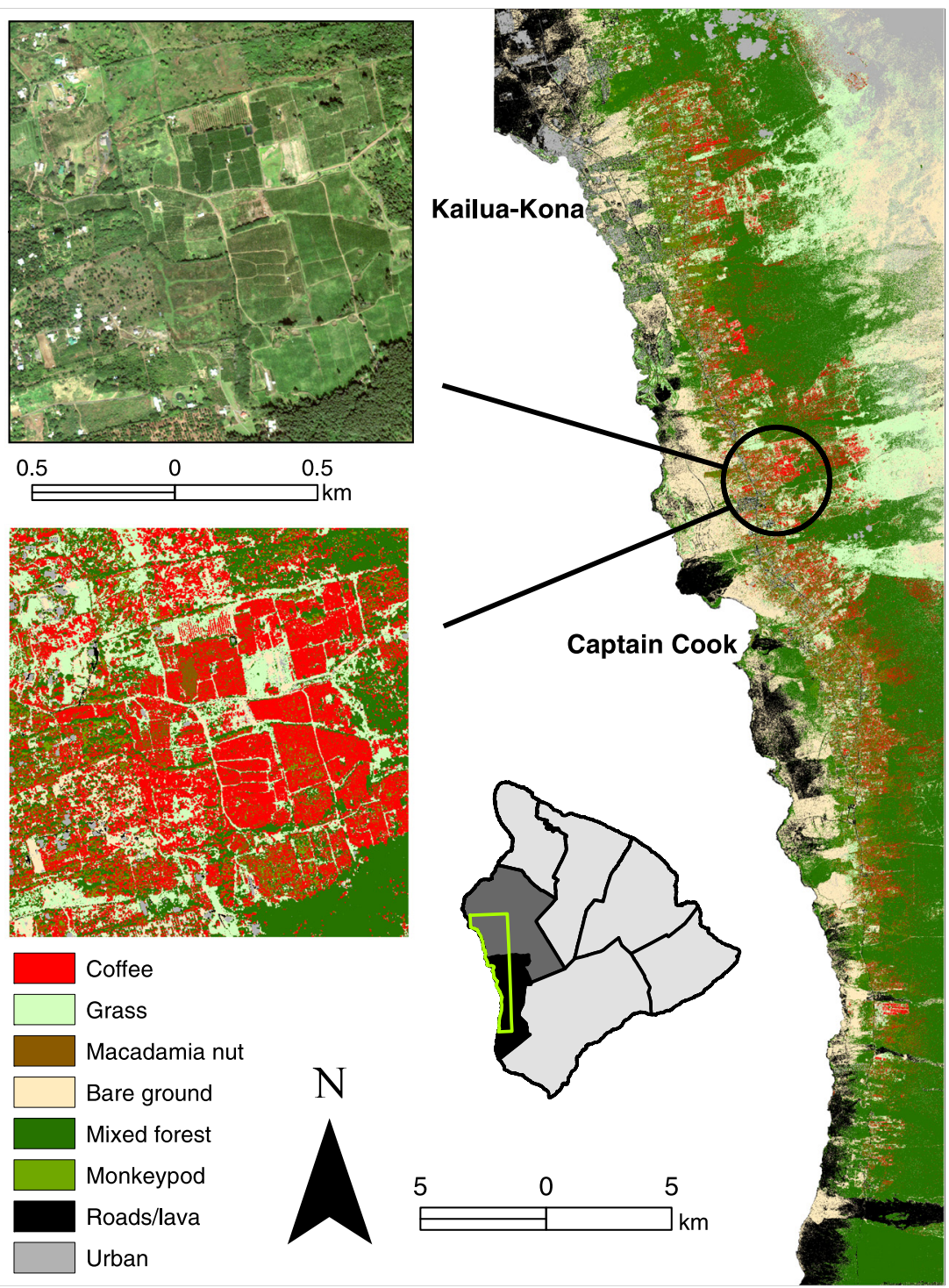

Fig. 2 Maximum likelihood (pixel-based) vegetation classification of the Kona coast in Hawaii.

Often macadamia nut trees are used as an over-story crop with shade coffee planted beneath. There was also weak spectral separability between coffee and mixed forest $(-1.270)$ and coffee and monkeypod (-1.389). The training dataset for the pixel-based method was tested for spectral separability in ENVI 5.2, which applies the Jeffries-Matusita, transformed divergence method for testing.

Some inaccuracy is introduced during the field data collection. As a general rule, the accuracy of the GPS unit used for defining training polygons should be appropriate for the resolution of the imagery and have an accuracy of one-half the size of the pixel. The accuracy of the Garmin Rino 655 used in this analysis was $\pm 3 \mathrm{~m}$, so there may be some error expected using this GPS unit without differential correction given the high spatial resolution and corresponding pixel size.

Coffee plants are found in various stages of growth on this landscape and can cover a range of growth habits, including feral coffee, abandoned coffee farms, cut stumps, weak or sparse coffee fields, mixed crops, and lush well-fertilized coffee fields. This adds a level of complexity to delineating a specific coffee spectral signature across this region using the classification algorithm alone. Despite these challenges, coffee fields are clearly visible in the classification maps, especially the one generated via OBIA (Fig. 3).

According to the Baseline Study for Food Self-Sufficiency in Hawaii County, there were $\sim 1660$ hectares of coffee crop under cultivation in Kona in 2012.27 The pixel-based classification 


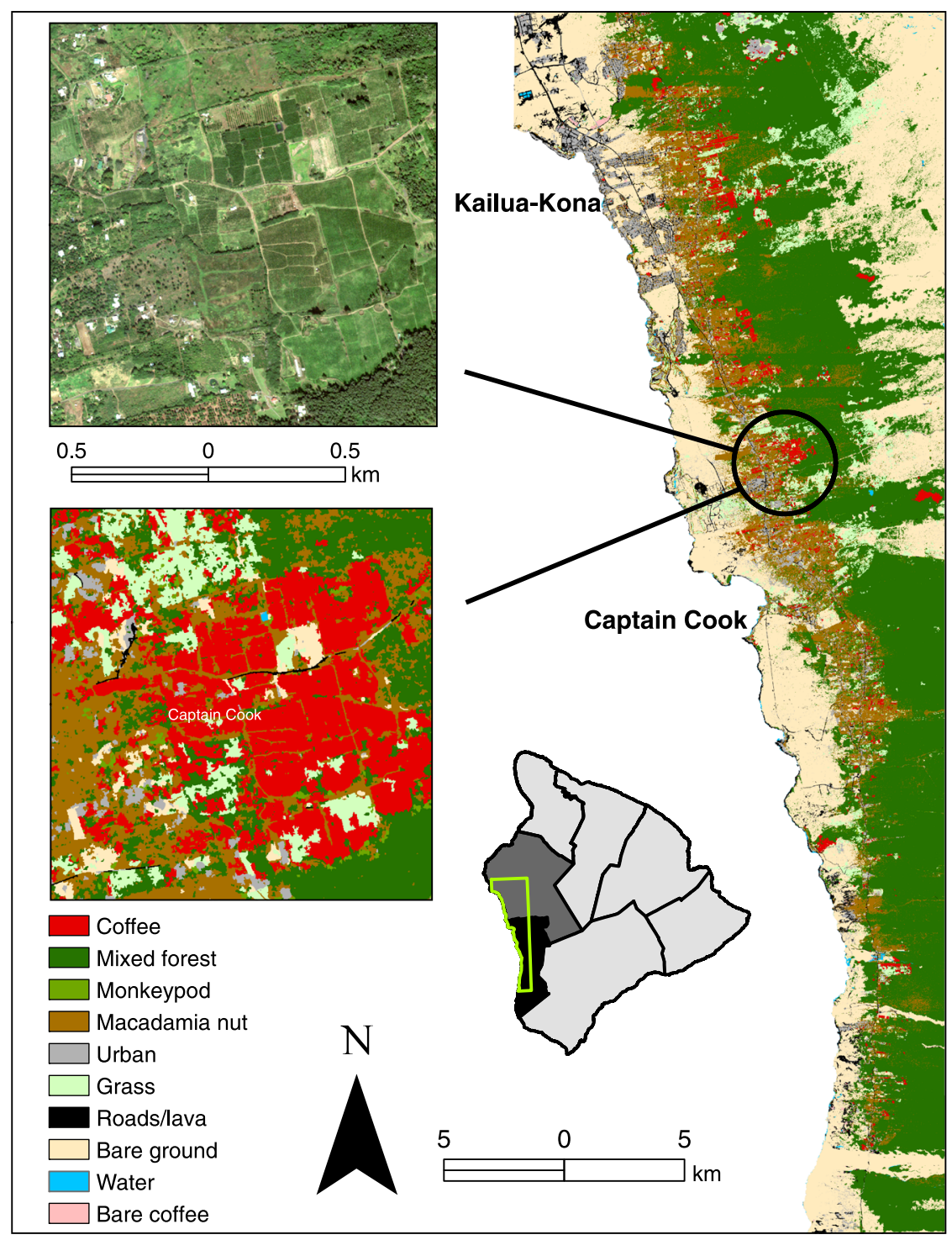

Fig. 3 Object-based vegetation classification of the Kona coast in Hawaii.

approach greatly overestimated $(+60 \%)$ the amount of coffee under cultivation compared with the Baseline Study, with 2650 hectares classified as coffee (Fig. 2). The object-based classification approach more conservatively estimates the amount of coffee under cultivation, yielding $\sim 1043$ hectares classified as coffee (Fig. 3). The difference of about 600 hectares (or 37\%) for the OBIA compared with the Baseline Study can be attributed at least partly to misclassification because, according to our accuracy results, there was an $\sim 25 \%$ error of omission rate for the coffee pixels under that method. Omission may be due to misclassification of fields that had recently been heavily pruned or stumped or not planted in rows-a practice observed in some of the older farms. In addition, much of the coffee grown in Kona is grown under shade or in mixed plots (about 890 hectares estimated to be mixed coffee and macadamia island-wide ${ }^{27}$ ). Despite these factors, the object-based classification seems to accurately represent the clumped nature of the coffee fields rather than the scattering of coffee pixels across the pixel-based image. It should be considered a lower estimate of the area under coffee cultivation on the island.

For the Kona coffee industry, specifically, the classification map presented here will be a valuable source of information on the physical characteristics of the areas under production. The distribution of elevation at which coffee is grown and the average field size can be calculated quickly based on the classification presented. The locations of coffee fields also can be related to 
various ecoclimatic parameters such as solar irradiation, soil types, and rainfall. Finally, the methods described here can be used to track changes in coffee agriculture in Hawaii via the classification of other WorldView images, such as WorldView-3 from January 2016. Specifically, questions on the increase or decrease of the overall area under coffee production can be assessed, and, in the longer-term, changes in elevation of coffee production following changes in climate could also be tested. Information from these will be especially important for grower groups and planners as the industry continues to respond to the invasion of the coffee berry borer and to prepare for future pests and changing climate.

Future research should pursue the generality of our application of the OBIA method used here for coffee detection. This will be especially interesting in areas where coffee rust (Hemileia vastatrix) is present (currently most of the coffee growing regions of the world), as this might affect the spectral signature of the plant ${ }^{209}$ In addition, it would be useful to apply this method to estimating changes in areas under coffee production over time by comparing classification results from images acquired in different years.

An online map viewer for quick viewing of the classifier outputs is available in Ref. B0. Within this online viewer, the maximum likelihood layer is labeled "Max Like WV2 Kona Coast" and the OBIA results are labeled "FX WV2 Kona Coast."

\section{Conclusion}

Coffee is an economically important crop in the tropics, so a remote mapping method is of value to those measuring coffee production and planning pest control since such a method could be executed at lower cost and more quickly than field data collection. In this study, we used a pixelbased classification method, maximum likelihood, and an OBIA classification method for detecting coffee from WorldView 2 satellite imagery of the Kona coffee growing region in Hawaii. Compared with the spectral-only pixel-based method, the OBIA approach was superior for detecting coffee fields, with an overall accuracy of $81 \%$ compared with $68 \%$ for the pixel classifier. In addition, OBIA was better at producing contiguous classifiers without requiring additional processing to generate polygons of expected coffee fields as the pixel-based method would require. The estimates from the OBIA classifier of area under coffee cultivation in Kona were lower than those from other surveys done through field work or tax records, attributable to misclassification, changes over time between the surveys compared, and understory coffee, which would not be detectable in the satellite imagery.

\section{Acknowledgments}

We would like to thank J. Melrose and D. Delparte for data coffee fields in Hawaii and the SDAV lab in the Geography Department at the University of Hawaii, Hilo, for logistical support. Opinions, findings, conclusions, and recommendations expressed in this publication are those of the author and do not necessarily reflect the views of the USDA. The USDA is an equal opportunity provider and employer. This work was funded by USDA-ARS as part of a project titled "Area-wide Mitigation and Management for Coffee Berry Borer Control." The authors declare that they have no competing interests.

\section{References}

1. F. Fao, Statistical Yearbook 2013: World Food and Agriculture," Food and Agriculture Organization of the United Nations, Rome, Italy (2013).

2. J. N. Wintgens, Coffee: Growing, Processing, Sustainable Production. A Guidebook for Growers, Processors, Traders and Researchers, lv + 983 pp., Wiley-VCH, Weinheim, Germany (2009).

3. D. Jaffee, Brewing Justice: Fair Trade Coffee, Sustainability, and Survival, University of California Press, Oakland California (2014).

4. R. Rice, "Coffee production in a time of crisis: social and environmental connections," SAIS Rev. 23(1), 221-245 (2003). 
5. D. W. Roubik, "Tropical agriculture: the value of bees to the coffee harvest," Nature 417(6890), 708-708 (2002).

6. J. M. Waller, M. Bigger, and R. J. Hillocks, Coffee Pests, Diseases and Their Management, CAB International, Oxfordshire, United Kingdom (2007).

7. D. Rodríguez et al., "A coffee agroecosystem model: II. Dynamics of coffee berry borer," Ecol. Modelt. 248, 203-214 (2013).

8. D. Rodríguez et al., "A coffee agroecosystem model: I. Growth and development of the coffee plant," Ecol. Modell. 222(19), 3626-3639 (2011).

9. C. Gay et al., "Potential impacts of climate change on agriculture: a case of study of coffee production in Veracruz, Mexico," Clim. Change 79(3-4), 259-288 (2006).

10. L. J. C. Garcia, H. Posada-Suárez, and P. Läderach, "Recommendations for the regionalizing of coffee cultivation in Colombia: a methodological proposal based on agro-climatic indices," PLoS One 9(12), e113510 (2014).

11. S. Cordero-Sancho and S. A. Sader, "Spectral analysis and classification accuracy of coffee crops using Landsat and a topographic-environmental model," Int. J. Remote Sens. 28(7), 1577-1593 (2007).

12. M. A. Ortega-Huerta et al., "Mapping coffee plantations with Landsat imagery: an example from El Salvador," Int. J. Remote Sens. 33(1), 220-242 (2012).

13. M. Castelluccio et al., "Land use classification in remote sensing images by convolutional neural networks," ArXiv Prepr. ArXiv150800092 (2015).

14. G. Kinro, A Cup of Aloha: The Kona Coffee Epic, University of Hawaii Press, Honolulu, Hawaii (2003).

15. R. Teuber, "Geographical indications of origin as a tool of product differentiation: the case of coffee," T. Int. Food Agribusiness Mark. 22(3-4), 277-298 (2010).

16. E. Burbano et al., "New record for the coffee berry borer, Hypothenemus hampei, in Hawaii," J. Insect Sci. 11(117), 1-3 (2011).

17. A. J. Woodill et al., "The economics of coffee production in Hawai 'i," Econ. Issues 25, 1-9 (2014).

18. D. O. Evans, R. J. Joy, and C. L. Chia, Cover Crops for Orchards in Hawaii, University of Hawaii, Honolulu, Hawaii (1988).

19. T. Blaschke, "Object based image analysis for remote sensing," ISPRS J. Photogramm. Remote Sens. 65(1), 2-16 (2010).

20. S. V. Stehman and R. L. Czaplewski, "Design and analysis for thematic map accuracy assessment: fundamental principles," Remote Sens. Environ. 64(3), 331-344 (1998).

21. R. G. Congalton, "A review of assessing the accuracy of classifications of remotely sensed data," Remote Sens. Environ. 37(1), 35-46 (1991).

22. C. Cortes and V. Vapnik, "Support-vector networks," Mach. Learn. 20(3), 273-297 (1995).

23. P. Mather and B. Tso, Classification Methods for Remotely Sensed Data, 2nd ed., CRC Press, Boca Raton, Florida (2009).

24. M. Pal and P. M. Mather, "Support vector machines for classification in remote sensing," Int. J. Remote Sens. 26(5), 1007-1011 (2005).

25. Harris Geospatial, "Support vector machine background (ENVI API) [Harris Geospatial Docs Center]," https://wwwhharrisgeospatial.com/docs/backgroundsvmgeneral.htm (7 April 2017).

26. H. Posada et al., "Stability across environments of the coffee variety near infrared spectral signature," Heredity 102(2), 113-119 (2008).

27. J. Melrose and D. Delparte, Hawaii County Food Self-Sufficiency Baseline 2012, Department of Geography and Environmental Studies, University of Hawaii, Hilo, Hawaii (2012).

28. A. C. Kushalappa and A. B. Eskes, Coffee Rust: Epidemiology, Resistance, and Management, CRC Press, Boca Raton, Florida (1989).

29. D. Cressey, "Coffee rust regains foothold," Nat. News 493(7434), 587-587 (2013).

30. "Hermes GIS Viewer," 2015, http://cquest|arc.nasa_gov:8399/flexviewers/hawaii_climate, (15 September 2017).

Julie Gaertner is an environmental scientist specializing in remote sensing and geospatial analysis. Her consulting work includes mapping invasive species throughout the Hawaiian 
Islands. She has partnered with federal, state, private, and nonprofit agencies to increase awareness and provide hazard mitigation maps. She holds a MS degree in tropical conservation biology and environmental science from the University of Hawaii-Hilo and a BS degree in forest resources and streamside studies from the University of Washington-Seattle.

Vanessa Brooks Genovese is a research scientist with California State University, Monterey Bay, working for the last 20+ years at the NASA-Ames Research Center on the CASA project, modeling the terrestrial carbon cycle. She develops global datasets used for studies of carbon and greenhouse trace gas fluxes and climatic change. She is an experienced remote sensing and GIS analyst with expertise in programming and development of scientific visualization tools.

Christopher Potter is currently a NASA senior research scientist in the Biospheric Branch at ARC. He has been a NASA science team member on the Large-Scale Biosphere-Atmosphere Experiment in Amazonia (LBA-ECO I and II), EOS Interdisciplinary Science, Intelligent Data Understanding, NASA's Astrobiology Institute, the Boreal Ecosystem-Atmosphere Study, and Land Surface Hydrology. He is the author of over 50 peer-reviewed journal articles and book chapters.

Kelvin Sewake received both his BS and MS degrees in horticulture from UH-Manoa, CTAHR. $\mathrm{He}$ is interim associate dean and associate director for extension, University of Hawai'i at Mānoa, College of Tropical Agriculture and Human Resources (CTAHR), and has administrative responsibilities for all of CTAHR's extension programs. He is the PI on a USDA-funded Area-Wide Coffee Berry Borer Mitigation program. He served most of his 32-year career as a county agent in floriculture with CTAHR.

Nicholas C. Manoukis does research focused on pest ecology, behavior, and biological control through a combination of field experiments and computer models. Most of his work is on tephritid fruit flies of economic importance in Hawaii and quarantine concern in the US mainland. He is the scientific lead on an Area-Wide Program on Coffee Berry Borer. Previously, he spent 8 years studying the ecology and behavior of the malaria vector A. gambiae in Mali. 